\title{
Maternally Derived Graft Versus Host Disease
}

National Cancer Institute

\section{Source}

National Cancer Institute. Maternally Derived Graft Versus Host Disease. NCI Thesaurus. Code C156790.

Graft versus host disease (GVHD) that occurs in an infant as the result of engraftment of maternal lymphocytes, resulting from in utero maternal-fetal cellular trafficking. 